\title{
Older Female Survivors of intimate Partner Violence in the Taiwanese Cultural Context
}

\author{
Chu-Li Julie Liu ${ }^{* 1}$ and Faye Mishna ${ }^{2}$ \\ ${ }^{1}$ Department of Social Work, Tunghai University, Taichung, Taiwan \\ ${ }^{2}$ Factor-Inwentash Faculty of Social Work, University of Toronto, Toronto, Ontario, Canada
}

\begin{abstract}
Intimate partner violence (IPV) causes severe physical and psychological damage to victims. Older IPV survivors are increasing around the world with the rapidly growing older population. Little is known about the needs of older female IPV survivors in the Chinese cultural context; the aim of this study was to examine the needs of older female IPV survivors in Taiwan. A grounded theory approach was adopted. Individual in-depth interviews were utilized to collect data. First-level coding, constant comparison among coding, then grouping coding into higher levels of categories and identifying a central story were employed to analyze data. Findings were compared to literature for further verification. Eight Taiwanese older female IPV survivors aged 60 to 74 were interviewed. The findings revealed that the cultural premise emphasizing the importance of family was a major contributor to participants' staying in abusive relationships. Four themes emerged in this study: 1) the marriage serving different purposes throughout the life course of the participants; 2) keeping the family whole enhances life satisfaction in older age; 3 ) working towards financial independence for lifetime security is an important goal; and 4) finding an independent space as a way of coping with the abusive relationship.

Implications for social work practice, in particular incorporating the cultural premise into developing viable options for older female survivors, are discussed.
\end{abstract}

Keywords: Cultures, family, independence, intimate partner violence, older females, Taiwan.

\section{INTRODUCTION}

Intimate partner violence (IPV) causes severe physical and psychological damage to victims [1]. Most IPV survivors are female. In Taiwan, $88 \%$ are female [2]. As the typical image of an IPV survivor is that of a young or middleaged woman with young children, interventions for IPV survivors are tailored to the needs of this group [3]. However, elder IPV survivors are increasing around the world, as the population rapidly grows older [4]. Therefore, understanding the experiences of older female IPV survivors and responding to their needs is particularly important.

Wilke and Vinton indicated that there are differences across age cohorts of female IPV survivors [3]. For example, older IPV survivors tend to stay in abusive relationships whereas young and middle-aged IPV survivors are more willing to consider leaving, and older female IPV survivors make fewer reports to the police. In addition, research indicates that for older female IPV survivors it is hard to differentiate physical wounds caused by abuse from those caused by age-related weakness or illness; this increases the likelihood that their IPV problems will be ignored by practitioners [5].

*Address correspondence to this author at the Department of Social Work, Tunghai University, 1727 Sec.4 Taiwan Blvd, Taichung, Taiwan; Tel: (+886) 04-23590121, Ext. 36505; Fax: (+886) 04-23594226;

E-mail: chuli@thu.edu.tw
A search of the electronic databases such as SocIndex and ERIC, shows that research focusing on understanding the needs of older female IPV survivors is mainly conducted in the Western world, whereas little is known about their needs in the Chinese cultural context. Since the reported number of older female IPV survivors in Taiwan has been increasing [6], there is a need to focus on understanding them. The aim of this study is to examine their needs.

\section{BACKGROUND: TAIWAN'S RESPONSE TO INTI- MATE PARTNER VIOLENCE}

In recognition of the problem of violence against women, the Domestic Violence and Sexual Assault Act was enacted in Taiwan in 1998. The following year, services aimed at the protection of women and mediation of the effects of IPV were launched [7]. Domestic Violence and Sexual Assault Centers under the Department of Social Affairs of City Government were established with a mandate to help battered women and their children during crisis. Additionally, there is a network of "contracted out" social service agencies that are charged with the responsibility of assisting battered women in rebuilding their lives after the time of crisis. Cases of IPV are first reported to the Domestic Violence and Sexual Assault Centers, either by frontline social workers in agencies such as those in health settings or by police officers. Upon receiving the report, social workers with the city government are required to visit the women and collect data within 72 hours, file the case before the court, and ensure the victim's 
safety. Battered women and their children are assisted in relocating to a women's shelter if it is determined that they are subjected to threatening/unsafe situations.

Social workers subsequently assist IPV survivors in obtaining protective orders through the courts to keep the abusers away from their workplace or to protect them should they decide to return to the abusers. Once free of immediate danger, the IPV survivors are referred to contracted-out social service agencies. The victimized women are helped to develop plans to rebuild their lives and are provided with needed resources, such as temporary shelter, financial aid or job training, and referrals for legal services.

\section{THE CULTURAL CONTEXT OF OLDER FEMALE IPV SURVIVORS IN ASIA}

Because there is an absence of literature on older female IPV survivors in Taiwan, we begin with a review of the literature in Asian cultures generally, to provide an understanding of the concerns and issues that face older female IPV survivors in societies with similar cultural traditions. Asian cultures, in particular those of Taiwan, China, Korea, and Hong Kong, are predominantly imbued with Confucian ideology, which emphasizes family-centered values and interpersonal relationship rituals [8]. According to familial rituals, men lead and represent the family whereas the virtue for women is to follow $[9,10]$. Women are to be submissive wives, obedient daughters, and caring, self-sacrificing mothers. The ideology dictates that married women regard their husband's family as their first priority. When they have children, being a parent becomes the most important priority [11]. Self-sacrifice is considered a virtue of women and a way of coping with difficulties.

In countries including Taiwan, China, Hong Kong, and Korea, these precepts influence attitudes towards abused women across all age groups in a number of ways that remain relevant in the Chinese context: entrenched views of male privilege and female submission [12]; the belief that women are responsible for their abuse [10, 13]; the importance of honoring family and the primacy of family relationships, including the extended family [14]; wives' conflict with in-laws (husbands' family members), as such conflict implies disrespect by a wife of her husband's family members [15]; and barriers to publicly disclosing negative feelings and events $[16,17,18]$. These beliefs lead to an overall culture of concealment of abuse and victim-blaming attitudes [18-20].

A life course perspective is useful in exploring older females' needs resulting from the cumulative effects of their vulnerability across the life span, their social location, and the social context in which they grew up [21]. Taiwanese women who are older than 60 were raised in an era characterized by authority and militarization; martial law was implemented from 1949 to 1989 and male domination was strict. The emphasis in this era was on women staying at home and taking care of their husbands [22, 23]. Although many women who are older than 60 participated in the labor market when they were young, they eventually followed this gender-specific path [24]. In addition, although they participated in the labor market and had income of their own, they were not considered equal breadwinners, but were subordinated to their husbands [25].

Many older female IPV survivors are reported by practitioners to lack motivation to ask for help or leave the abusive relationship [26]. However, they indicated that the reason should be traced back to the context in which the survivors were socialized [26]. Older females in Asian cultures imbued with Confucian ideology were socialized to be economically dependent on their husbands, and thus were not able to survive or live independently if they left them. Patterson also indicated that because many older women in such Asian cultures are not allowed to make decisions on their own, they are unfamiliar with the possibility; the idea that women should take family members' views - in particular those of their parents and elder male siblings - into consideration when deciding whether to leave a marital relationship, also contributed to their difficulties or unwillingness to leave abusive relationships [27]. In addition, in such Asian cultures, interpersonal violence is considered a shameful family event that should be hidden $[14,20,28]$. In these cultures, not only the survivors but other family members helped conceal this secret $[14,20]$. Such concealment was even stronger in the era when Asian women over 60 grew up, suggesting that it contributes to older female IPV survivors' unwillingness to leave abusive relationships because that might reveal the abuse to outsiders [20,28]. Nevertheless, elders in Confucian cultural contexts consider it a blessing that people have family around, including their adult children, to care for and respect them in their old age [29-31]. This cultural concept of ideal aging may be an additional contributing factor to older female IPV survivors' unwillingness to leave abusive relationships.

Deciding to go to a women's shelter is another issue for older female IPV survivors living in these cultures. Confucian cultures emphasize the family as a whole, harmonious interpersonal relationships, and wives' subordination to husbands; they put the importance and honor of family before the individual [32]. Therefore, the act of moving to a woman's shelter signals the end of the relationship; it clearly breaks up the family as a whole. Moreover, being in a woman's shelter may bring shame to the family in countries with Confucian cultural backgrounds. Therefore, most older female IPV survivors with such backgrounds reject the idea of moving to a shelter even it is a way to improve their lives [28].

The health condition of their husbands may also affect the decision and actions of older female IPV survivors. Caring for an ill husband is often considered the wife's responsibility. Beaulauirer, Seff, Newman and Dunlop indicated that if an older female IPV survivor is the major caregiver for her abusive ill husband, it is even more complicated for her to decide whether to stay or leave [33].

\section{METHODOLOGY}

As the nature of the research is exploratory, a qualitative research method was adopted in this study. Research procedures followed the paradigms of grounded theory. A grounded theory approach is suitable when a theory or model is not available, is incomplete, or is based on populations other 
than the sample in the study [34]. It is appropriate for this study because there is little to no literature on older female IPV survivors in Taiwan.

\section{Recruitment}

Letters of introduction that included an explanation of the study, selection criteria for participants (female IPV survivors who were 60 or older and were service recipients), and interview guidelines containing samples of interview questions were mailed to Domestic Violence Service Centers and to the social service agencies in Taiwan to seek their agreement to participate in this study. After gaining agreement and ethics approval from these agencies and the University Ethics Review Committee of the first author, we distributed letters of introduction to social workers to recruit participants. Social workers who had worked with older female IPV survivors contacted them first to see if they agreed to participate in this study. Upon receiving survivors' consent to take part, social workers arranged a time and a quiet room in the social work agencies for survivors and the first author to meet. This process was followed to ensure the confidentiality of personal contact information.

\section{Sampling Method and Characteristics of Participants}

Purposive and snowball sampling were employed to locate female IPV survivors aged 60 years or older who had been helped by social work practitioners. In Taiwan, individuals older than 65 are considered to be elders in official documents and policies. Since individuals who are 60 years old are considered elders in some other countries [35], we recruited female IPV survivors who were 60 or older from various cities and counties in Taiwan, including Taoyuan, Miaoli, Tainan and Kaoshiung, in order to maximize the range of experiences of participants to gather rich information. There are fewer older female IPV survivors compared to middle-aged and young survivors, although the number is increasing along with the ever-growing older population. The first author first contacted the Domestic Violence Prevention Centers and social service agencies in all cities in Taiwan to recruit participants; social workers in Taipei City, Taichung City, Yilan County, and Hwalien County in Taiwan reported that they did not have clients who met the selection criteria for this study. Only one county, Chunghwa, refused to participate in this study because social workers reported being too busy. Therefore, the author stopped recruiting participants and collecting data after interviewing eight participants.

Eight female IPV survivors between the ages of 60 and 74 were interviewed. Six of the participants were married, one was divorced, and one participant's abusive male partner passed away during the time of the study. All of the participants have adult children. Three participants were from Kaoshiung City, a metropolitan city; two from Tainan City, a rural city; one from Miaoli County, a rural area; and two were from Taoyuan County, an urban county. The details of participants' background are illustrated in Table $\mathbf{1}$.

\section{Data Collection}

Data collection involved the use of the long interview method [36], an in-depth interview process that enabled the first author to explore participants' reflections on the abuse they experienced by their male partners and on their needs. In-depth interviews lasting approximately two to three hours were conducted in Chinese by the first author, in a safe and quiet office in either a domestic violence center of city government or a "contracted out" social service agency, between November 2011 and June 2012. An interview guide included questions such as "Tell me about your experiences of being abused by your male partner" and "Tell me about your needs while encountering the abuse." The first author wrote field notes after each interview to assist the data analysis. Since the interviews were conducted in Chinese, the transcripts were read and analyzed in Chinese in order not to lose any nuances of the dialogue. Only the quotes in this article have been translated into English.

\section{Data Analysis}

Line-by-line review of the transcripts was conducted and first-level codes (descriptors of important components of the interviews), including in vivo codes (using the participants' language), were noted in the margins $[37,38]$. The next step comprised constant comparison [37,39] and refining and organizing the first-level codes into categories. For example, a higher category - "marriage served different purposes throughout the life course of participants"-was adopted to organize participants' various reasons for staying in the abusive relationship such as escaping poverty while young, not wanting their children to grow up in a "broken" family, and the influence of karma for them as they aged. As another example, a higher category- - "finding an independent space for herself in the abusive relationship"-was adopted to organize strategies participants mentioned strategies using to enable them to remain in the abusive relationship, such as staying in a separate room or in the staff's room, hiding in the corn field, or talking to the priest to search for the meaning of their suffering. Theoretical coding was undertaken to identify higher-level codes and relationships among categories in order to ensure saturation of categories [37], after which a central story emerged and was developed. The results correspond to the emergent categories. After four categories were identified, a central story line, "cultural premises that guide Taiwanese older female IPV survivors in abusive relationships," was developed to organize categories. Findings were compared to the literature for further verification.

\section{RESULTS}

This study indicates that cultural premises that emphasize the importance of family contributed to participants' staying in abusive relationships. Navigating to independence, in particular financial independence and an independent space, helped participants to psychologically detach somewhat from the abusers, repair dignity, and regain strength. Four themes emerged through analysis of the interview data: 1) the mar- 
Table 1. Participants' background information.

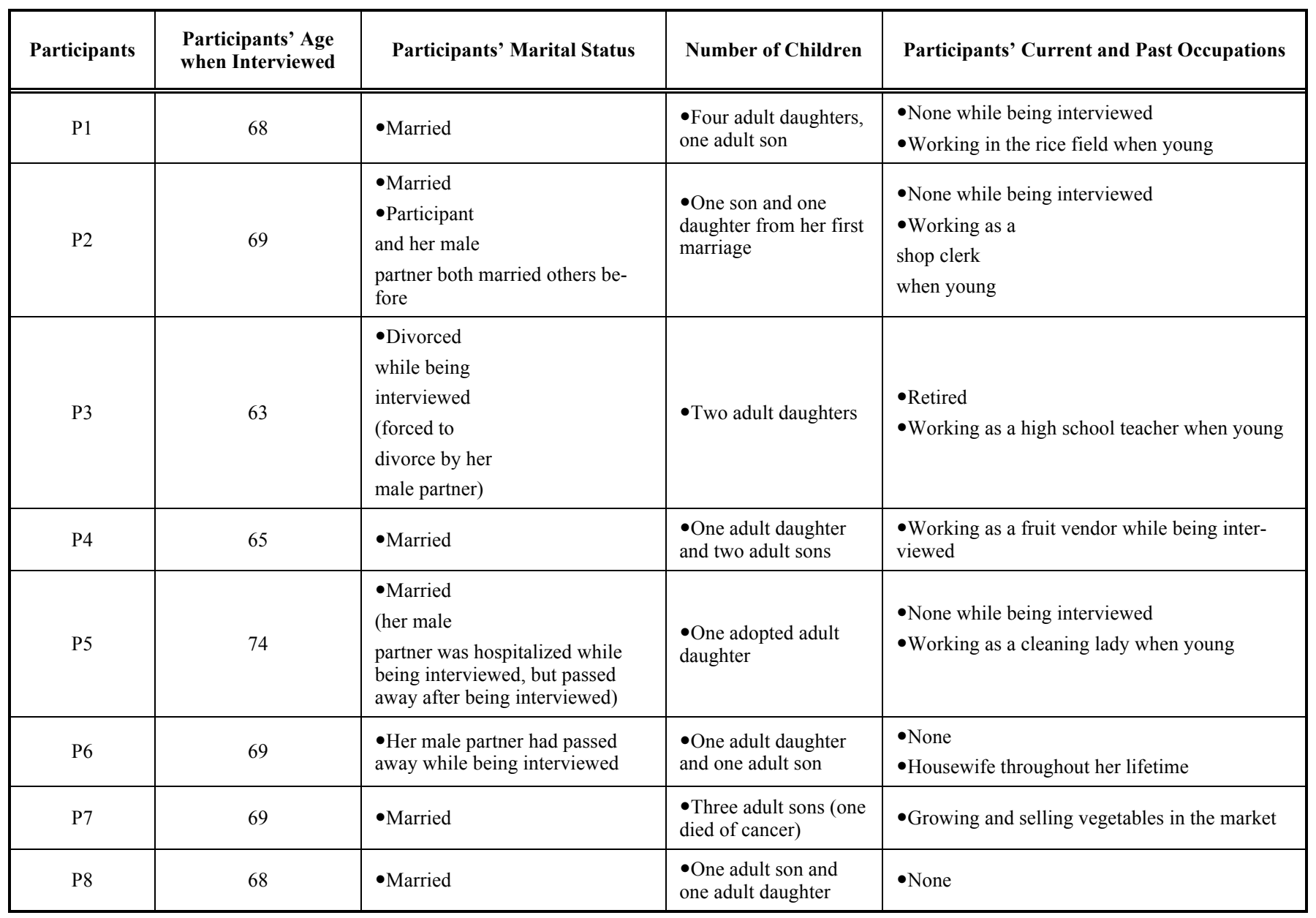

riage served different purposes throughout the life course of the participants; 2) keeping the family whole enhances life satisfaction in old age; 3 ) participants worked towards financial independence for lifetime security; and 4) they tried to find an independent space in the abusive relationship.

\section{The Marriage Served Different Purposes throughout the Life Course of Women}

All of the participants grew up in an era in which Taiwan's social context was conservative; marriage was women's ultimate destiny, and women's subordination to men was integral, and there was no discussion about human rights. The participants all reported that marriage was a way to realize their dreams, including escaping poverty and being able to enter the higher social class of which they dreamed.

Marriage seemed to make all of the participants' dreams come true (P1, P2, P3, P4, P5, P6, P7, P8) when they were newly married. It became evident, however, that their relationships were abusive, and the women suffered throughout their lives. One participant (P1) who was illiterate reported growing up in a very poor peasant family, working in the rice fields as a little girl, and dreaming of escaping her poor family of origin.

I worked as a laborer since I was a little girl. I worked so hard and felt so tired, so I felt if I could marry someone like a businessman that would be absolutely great (P1)
One day her cousin introduced her to a man who was financially better off; she soon married him because it was the only legitimate way to escape her impoverished family. She has three daughters and one son. She said that though she was constantly beaten by her husband when her children were young, she worked hard to keep the marriage and never considered leaving, because she wanted her children to have their father present at their weddings. She did not want her children to be stigmatized as growing up in a "broken family."

\section{Maybe I am stupid to stay, I did not want to leave this abusive marital relationship, I can- not leave my kids behind, alone, my kids were so young and they needed me. Also my kids de- served to have a father (PI)}

Several other participants (P4, P5, P6, P7, P8) who had impoverished childhoods reported comparable stories; marriage helped them escape from poverty, and despite abuse they wanted to keep the marriage so that their children would not have broken families.

I think that it is my fortune to be poor and that I am destined to sacrifice myself in this abusive relationship, I have already accepted that. But my abusive partner is the father of my three kids; I could not leave this marriage. No 
matter what he has done to me, he is my kids'

father. That is important (P7)

The partners continued to beat the participants after their adult children were married. Even though their reasons to stay in their abusive relationships no longer existed, the participants still wanted to stay. Most participants (P1, P4, P5, P6, P7, P8) described their reason for staying in terms of "karma," a popular Taiwanese folklore belief. They felt they were destined to marry their abusive partners and stay with them to the end due to deeds of theirs in a previous incarnation.

\section{Maybe I owed my male partner a lot in my previ- ous life, so I am meant to be tortured by him in this life in order to pay what I owed him (P7).}

As one participant put it,

I told myself that there is no need to figure out whether I should leave this relationship. I told myself probably I owed him too much in my previous life, so if being tortured by him is a way to pay him back, then it is ok, I will settle what I owe him in this life. I don't want to carry it to my next life, it is karma. Then maybe I will have a happy relationship in my next life (Pl)

They believed keeping the marriage was a way to overcome karma that helped them wash away their sins and symbolically pay their debts.

\section{Keeping the Family Whole Enhances Life Satisfaction in Old Age}

Participants (P1, P2, P4, P5, P6, P7) in this study reported that being alone in their old age is considered a misfortune in the Taiwanese cultural context, whereas keeping the family together is thought to provide a sense of completeness to individuals in their old age, thus enhancing their life satisfaction. In Taiwanese culture, the husband's family is considered to be a woman's ultimate refuge and the center of women's lives. According to participants, "being alone" refers to a woman who does not marry and therefore does not have an ultimate refuge. Participants who were able to keep the family whole in their old age are referred to as women with virtue.

One participant (P7) who was a vegetable farmer reported that she had adopted a number of strategies to cope with the abusive relationship, including hiring Taiwanese folklore priests to host several worship ceremonies; she was given Chinese herbs by these priests to take home in order to remedy her partner's violent behavior and to give her the strength to work through the abuse.

\section{I took the herb home and let it stand for seven days, then soaked it in water, then poured the water on the tree in our yard. However, it did not work at all. My male partner beat me even more (P7)}

She explained that such strategies were common in her village. Although these ceremonies did not appear effective, her action demonstrated this participant's commitment to keep the family whole. She said it is a blessing for an aged person to have the family around and she therefore put all her efforts into keeping the family together.

I am so happy I am able to see my kids grow up as good persons and that I have them around me. I feel satisfied that I belong to a family although I have been abused (P7)

Keeping family together is my ultimate wish...divorce leads me to nowhere (P2)

\section{Looking for Financial Independence for Lifetime Security}

The participants began to experience abuse soon after marriage. They accumulated much suffering and traumatic experience throughout the course of their lives, struggled tremendously, and felt helpless and hopeless in the relationship. All participants reported that they had realized that their male partners were not reliable, so that they needed to look for another source of security - financial independence.

One participant (P5) who was in her 70s said her abuse by her partner made her realize quickly that only financial independence could offer her lifetime security.

Our marital relationship is not happy; we never celebrate our wedding anniversary, my male partner never buys gifts for me. If I need anything, I buy it myself. My male partner only offers me food (P5)

As she received little formal education, she worked as a cleaning lady in a hotel and worked hard to learn to speak Japanese after work. She was eventually promoted to chief of the cleaning staff because of her ability to communicate with Japanese customers.

I worked in a hotel. I was able to speak Japanese better than other cleaning staff and I seldom took sick leave, so I made lots of tips and saved them as my own money. I am thrifty. I also helped people clean their houses after work and saved the hourly wages as my own money (P5)

Having her own money made her feel self-reliant and fearless despite constant beatings by her partner. The money helped her rebuild the sense of autonomy that had been lost in the abusive relationship.

Another participant (P3), who had been a high school teacher, conveyed a similar story. She added that while the marriage made her feel like a failure, having financial independence gave her a sense of accomplishment.

I have a salary, my own income. The salary allows me to look after myself, for example, as a geography teacher, I love traveling; my own income allows me to travel during summer or winter break, which gives me a sense of accomplishment. My marriage gave me a sense of failure (P3)

\section{Looking for an Independent Space in the Abusive Rela- tionship}

The participants had all developed strategies to cope with their abusive relationships while keeping their family together. Most participants (P1, P2, P3, P5, P6, P7, P8) utilized the 
metaphor "creating an independent space" to describe this strategy. "Creating an independent space" referred to staying in a separate room in the same house, hiding in the cornfield, or joining church activities to search for spiritual explanations for suffering.

We live under the same roof, but my male partner has his own life. I have my own life; I stay in my own room, I lock the door when I am in my room; and sometimes I take a walk myself. These strategies gave me the strength to go on (Pl)

I hid in the cornfield when my male partner was drunk and beat me violently. It helped me escape from the beatings because he was too drunk to run after me (P7)

One participant (P2) was the caregiver for her abusive partner, who was diagnosed with dementia during the time she participated in the study. Her partner controlled every aspect of P2's daily life and since their marriage had limited her contact with persons or events outside their family. When her partner became ill and was hospitalized, she attended church activities and talked to the priest about her suffering. She described this as her own space that allowed her to search for meaning and to receive support from others. This metaphor of her own space helped the participant regain the psychological strength to maintain the marriage and to continue to care for her partner.

I go to church when I have free time. Everyone there is nice and reads the Bible with me. The priest told me that the sin of everyone in my family was forgiven because I believe in God; this helps me to ease the pain of the abuse (P2)

She explained that on one occasion a social worker helped her to obtain a court order to protect her from being beaten by her partner, but that this was not useful, since she was the only person who could care for her partner and his cognitive limitations prevented him from understanding the meaning of a protective order. Thus, for this participant the legal service was not helpful but going to her own space (church) was.

The protective order is not useful for me. My husband does not understand it and it breaks the harmony of my family, as our adult children do not want to see me adopting this way to solve the problem (P2)

Similarly, the participant from a peasant village (P1) adopted a strategy whereby she would stay in a separate room in the house as a way of staying in the abusive relationship. This participant cooked and did all the housework for her partner and other family members, but did not share the master bedroom; rather she slept and stayed in a room of her own. This strategy allowed her to maintain physical distance from her partner, giving her some peace of mind in the midst of the abuse. This participant revealed that a social worker had once tried to place her in a woman's shelter because her partner had broken her arm. She found it more helpful, however, to stay in her adult daughter's house for a period of time. Going to a woman's shelter complicated the situation with her adult children, whereas staying with her daughter seemed to serve this participant's purpose of creating a space for herself. Another two participants, the vegetable farmer (P7) and the hotel cleaning lady (P5), reported similar stories; the only difference was that the vegetable farmer often stayed in the cornfield and the hotel cleaning lady stayed in the hotel staff room to escape from their violent situation.

Going to an independent space provided participants with temporary safe places in which to regain strength to stay in their abusive relationship. Going to a woman's shelter or obtaining a court order did not seem viable options for participants in this study.

\section{DISCUSSION}

An important finding of this study is that deeply embedded cultural premises guided participants in the midst of abusive relationships. The first theme that emerged - that marriage served different purposes throughout the life course of women-revealed that participants endured the abuse and sacrificed themselves to keep the marriage at all costs due to their belief it was good for their children and that this was a way of overcoming their karma. Participants in this study were all over 60 and grew up in Taiwan during an era (the 1950s) when the cultural message was that women should marry, remain at home, and take care of their husbands and children; their subordination to men was much more strongly entrenched than it was for young and middle-aged women $[22,40]$. According to this cultural message, virtuous women would do their best to maintain their marriage [23]. Therefore, endeavoring to maintain the marriage at all costs represents older females' most important goal. This largely explained why participants worked to keep the marriage despite the chronic abuse by their partners. Additionally, to help them remain in the marriage participants utilized the concept of "karma" - a Taiwanese folklore belief that to the participants meant that they were destined to marry their abusive partners as a result of deeds in their previous incarnation [41].

The second major theme that emerged was that of keeping the family whole as a way of enhancing life satisfaction in their old age. In addition to the cultural premise regarding the importance of family, an important Taiwanese cultural belief is that it is a blessing when elders of both genders are surrounded by their family and respected by their children. This cultural premise implies another precept for women in particular - that having a husband and family around when a woman is older symbolically indicates that she has an ultimate refuge [42], which is important for women in Taiwan. This premise increases understanding of why participants were satisfied to have the family around in their old age, which is supported by findings [9, 10, 29, 31], whereby wellbeing is considered by elders with backgrounds in Confucian ideology to be primarily related to family.

The first theme-marriage served different purposes throughout the life course of women-and the second theme-keeping the family whole enhances life satisfaction in old age - revealed that participants stayed in abusive relationships largely due to cultural beliefs. This finding seems to be both somewhat in contrast to and consistent with the views of Patterson [27], who suggested that Asian women 
were not allowed to make decisions on their own and they were therefore unfamiliar even with the possibility of doing so. In the current study, it seemed participants were familiar with the option of leaving or staying in their relationships. However, they had very limited choices and appeared to remain in their relationships in large part due to entrenched cultural beliefs and their own personal life histories. Harbison posited that the reasons older female IPV survivors did not want to leave should be traced back to the contexts in which they were socialized [26], which supports the findings of this study.

The third and fourth emerging themes-looking for financial independence for lifetime security and looking for an independent space in the abusive relationship -indicated two ways in which participants seemed to find some form of independence in the midst of their abusive relationships. Independence, referring to financial independence and separate space, helped participants to psychologically detach somewhat from their abusers and repair themselves to some degree, which helped them stay in the abusive relationships. Since leaving the abusive relationships did not feel feasible for the participants because of their cultural context and personal history, they were trapped in a familial relational system that was dangerous for them, and in which they were devalued. Therefore even the very limited independence participants found and carved out provided them with protection psychologically and physically. Paradoxically, the "independence" participants endeavored to create in these chaotic abusive relationships helped them to stay. This ironic finding is not discussed in the current literature regarding Asian older female IPV survivors.

Participants in this study are all long-term sufferers and realized early in their abuse experience that they could not rely on their partners. Reporting that money was the most important resource for their practical survival, participants worked towards gaining some financial independence for their lifetime security before entering into their old age. Participants worked and saving their own money was a priority. Most of the participants worked in jobs in which they were paid by the hour; one was a farmer who sold vegetables in the farmers' markets; thus, they did not have official income statements. Therefore participants were able to hide some of their income as their own money, which their partners never knew about. This financial independence provided them with concrete and psychological security in the midst of abusive relationships from that time on.

In addition to financial independence, most participants used the metaphor of creating an independent space; that included staying in a separate room, going to church, and hiding in the cornfield to cope. These spaces and activities that fit into the participants' life arrangements provided them with a temporary safe place and protection away from their abusive partners. These spaces seemed to help participants repair themselves psychologically in the midst of the chronic abuse they endured. An additional finding to examine is that participants did not consider going to women's shelters and obtaining court orders helpful or applicable to them. In large part due to their age, the participants had quite different experiences and expectations from many young and middleaged females. Based on the results of this study, it may be important to expand options for older IPV survivors beyond women's shelters and court orders. A challenge is finding options that offer safety. This supports the findings of Shim and Nelson-Becker [28]. An example that became evident in this study - that participants considered moving into their adult children's houses - is more applicable to older IPV survivors. However, this alternative may not remove sufficient danger. It is therefore critical in working with older female IPV survivors to explore and develop options that can minimize the complexity of moving them to women's shelters while ensuring their safety. This suggests that in developing feasible and safe options for elder survivors that offer safety it is necessary to take the embedded cultural beliefs and contexts of these women into account.

\section{LIMITATIONS}

Due to the exploratory nature of this study, the findings cannot be generalized to other populations of survivors. The small sample size is a difficulty in developing a wellsaturated theory. Nevertheless, our findings elucidated specific elements of female older IPV survivors' experiences $[34,43]$. However, based on the descriptions and quotes derived from interview transcripts, our study asserts it is reasonable to utilize the findings in similar contexts [44].

\section{IMPLICATIONS FOR SOCIAL WORK PRACTICE}

Based on the findings of this study, implications for social work practice with older female IPV survivors with a background of Confucian ideology are suggested as follows:

1. Both age and cultural lenses should be adopted by social work practitioners to understand the unique needs of female IPV survivors.

2. The unique strategies that older female IPV survivors adopt must be understood in the context in which they were socialized.

3. Since keeping the family whole is considered foremost, in particular for older females with Confucian ideology backgrounds, it is critical to examine the viability of options such as placing survivors in a woman's shelter, obtaining legal services, or leaving the abusive relationship. Alternative intervention strategies developed particularly for this group of older female IPV survivors (for example, temporarily staying with their adult children when applicable and safe) are suggested, in particular to examine viable options including working with current strategies in a different way.

4. The strategy of creating an independent space in the midst of chaotic relationships seemed to help participants who were long-term survivors and who held family-centered cultural values. This has important implications for working with female survivors who have Confucian backgrounds. It suggests that creatively finding an independent, safe space is a possible intervention guideline to help survivors develop strategies while their family-centered cultural values are so strong and leaving the marital relationship is so difficult. This may be a temporary intervention while other issues are explored. 
5. The role of social work practitioners is to help older female IPV survivors develop coping strategies that include taking age and cultural lenses into account. While collecting information in the early stages of working with older female IPV survivors, social workers collect not only survivors' experiences and their history of being abused, but also the cultural premises that they have internalized regarding their roles as wives and mothers and being elderly. Social workers make assessments and develop intervention strategies that take these internalized cultural requirements into account. In addition, because older female IPV survivors often lack their own vehicles or have difficulties in using public transportation, the resources that social workers refer survivors to should be accessible for the survivors. Home visitation is a more appropriate way to work with older female IPV survivors.

\section{CONFLICT OF INTEREST}

The authors confirm that this article content has no conflict of interest.

\section{ACKNOWLEDGEMENTS}

This work was supported by the National Science Council, Taiwan (renamed Ministry of Science and Technology, Taiwan in 2014), Grant Number: NSC 100-2410-H-029-035 MY2. The authors thank their generous sponsor.

\section{REFERENCES}

[1] Desmarais SL, Reeves KA. Gray, black, and blue: the state of research and intervention for intimate partner abuse among elders. Behav Sci Law 2007; 25(3): 377-91.

[2] Ministry of Health and Welfare, Taiwan. Statistics of gender of intimate partner violence survivors [Online]. 2013 Nov 13, [cited 2013]. Available from: www.mohw.gov.tw/cht/DOPS/DM1.aspx? f_list_no $=143 \&$ fod_list_no $=1372$.

[3] Wilke DJ, Vinton $\overline{\mathrm{L}}$. The nature and impact of domestic violence across age cohorts. Affilia 2005; 20(3): 316-28.

[4] Cook JM, Dinnen S, O’Dennell C. Older women survivors of physical and sexual violence: a systematic review of the quantitative literature. J Womens Health 2011; 20(7): 1075-81.

[5] Yechezkel R, Ayalon L. Social workers' attitudes towards intimate partner abuse in younger vs older women. J Fam Violence 2013; 28: 381-91.

[6] Domestic Violence and Sexual Assault Prevention Committee, Ministry of Interior. Statistics of intimate partner violence survivors by age [Online]. 2013 March 28, [cited 2013]. Available from: http://dspc.moi.gov.tw/public/Attachment/32617485771.xls.

[7] Domestic Violence and Sexual Assault Prevention Committee, Ministry of Interior. Introduction to the committee. [Online]. 2008 July 7, [cited 2011] Available from: http://dspc.moi.gov.tw/ct.asp? $\mathrm{xItem}=1380 \& \mathrm{CtNode}=602 \& \mathrm{mp}=5$.

[8] Tweed RG, Lehman DR. Learning considered within a cultural context: Confucian and Socratic approaches. Am Psychol 2002; 57(2): 89-99.

[9] Lee MC. The changing roles and changing personality types of Chinese women. In: Proceedings of the Conference of the Population Studies Center, National Taiwan University; 1985, National Taiwan University. Taipei: National Taiwan University 1985.

[10] Tang C, Cheung F. Effects of gender and profession type on definitions of violence against women in Hong Kong. Sex Roles 1997; 36(11/12): 837-49.

[11] Xiong XG. Women's status in the Confucian paradigm. J Philos 1998; 24: 100-17.
[12] Lim IS. Korean immigrant women's challenge to gender inequality at home: The interplay of economic resources, gender, and family. Gender Soc 1997; 11(1): 31-51.

[13] Tang C, Wong D, Cheung F. Social construction of women as legitimate victims of violence in Chinese societies. Violence Against Women 2002; 8(8): 968-96.

[14] Yoshihama M. A web in the patriarchal clan system: Tactics of intimate partners in the Japanese sociocultural context. Violence Against Women 2005; 11(10): 1236-62.

[15] Chan KL, Brownridge DA, Tiwari A, Fong DY, Leung WC. Understanding violence against Chinese women in Hong Kong. Violence Against Women 2008; 14(11): 1295-312.

[16] Almeida RV, Doland-Delvecchio K. Addressing culture in batterers intervention: the Asian Indian community as an illustrative example. Violence Against Women 1999; 5(6): 654-83.

[17] Cousineau MM, Rondeau G. Toward a transnational and crosscultural analysis of family violence. Violence Against Women 2004; 10(8): 935-49.

[18] Preisser AB. Domestic violence in south Asian communities in America. Violence Against Women 1999; 5(6): 684-699.

[19] Chen S. The process of mate selection, experiencing abuse, and help-seeking of spouses from Mainland China. Commun Dev Q 2003; 101: 182-99.

[20] Tsang AY, Sung P. The social construction of concealment among Chinese women in abusive marriages in Hong Kong. Affilia 2005; 20(3): 284-99.

[21] Browne C. A feminist life span perspective on aging. In: Van Den Bergh N, Ed. Feminist practice in the $21^{\text {st }}$ century, Washington, D.C.: NASW Press 1995; pp. 330-54.

[22] Hsu FT. The study of the women's movement and women's discourse during the post-war period in Taiwan (1945-1972) Masters thesis. Taichung: Tung-Hai University 1996. (Chinese).

[23] Lee MC. Gender and gender role. Indigenous psychological research in Chinese societies 1996; 6: 260-99. Chinese.

[24] Lu YS. The relationships among women's participation in the labor market, family roles and power structures. Bulletin of Ethnography, Academia Sinica, Taiwan 1983; 56: 111-43.

[25] Lu YS. Women and family business. Paper presented at: 1997 Sociological Conference; 1997, Academia Sinica, Taipei, Taiwan; 1997.

[26] Harbinson J. Stoic heroines or collaborators: Ageism, feminism and the provision of assistance to abused old women. J Soc Work Pract 2008; 22(2): 221-34.

[27] Patterson FM. Heeding new voices: gender-related herstories of Asian- and Caribbean-born elderly women. Affilia 2003; 18(1): 6879.

[28] Shim WS, Nelson-Becker H. Korean older intimate partner violence survivors in North America: cultural considerations and practice recommendations. J Women Aging 2009; 21: 213-28.

[29] Laidlaw K, Wang DH, Coelho C, Power M. Attitudes to ageing and expectations for filial piety across Chinese and British cultures: a pilot exploratory evaluation. Aging Ment Health 2010; 14(3): 28392.

[30] Mjelde-Mossey L, Walz E. Changing cultural and social environments: Implications for older east Asian women. J Women Aging 2006; 18(1): 5-20.

[31] Yue X, Ng Sik H. Filial obligations and expectations in China: Current views from young and old people in Beijing. Asian J Soc Psychol 1999; 2: 215-26.

[32] King AYC, Bond MH. The Confucian paradigm of man: A sociological view. In: Tseng WS, Wu DY, Eds. Chinese Cultural And Mental Health, Academic Press 1985; pp. 29-45.

[33] Beaulauirer RL, Seff LR, Newman FL, Dunlop B. Internal barriers to help seeking for middle-aged and older women who experience intimate partner violence. J Elder Abuse Negl 2005; 17(3): 53-74.

[34] Creswell J. Qualitative inquiry \& research design: choosing among five approaches. Thousand Oaks, CA: Sage Publications 2007.

[35] Huang CC. A study of community elder abuse risk screening instruments: an example of in-home elder care from central Taiwan. Soc Policy Soc Work 2010; 14(1): 1-37.

[36] McCracken G. The long interview. Thousand Oaks, CA: Sage Publications 1988.

[37] Charmaz K. Constructing grounded theory: a practical guide through qualitative analysis. Thousand Oaks, CA: Sage Publications 2006 . 
[38] Glaser BG. Theoretical sensitivity: advances in the methodology of grounded theory. Mill Valley, CA: Sociology Press 1978.

[39] Glaser BG, Strauss AL. The discovery of grounded theory: Strategies for qualitative research. New York: Aldube de Gruyter 1967.

[40] Liu CL. A relational self model of gender role identity of young Taiwanese women within their cultural context. $\mathrm{PhD}$ [dissertation]. Waterloo (ON): Wilfrid Laurier University 2002.

[41] Tzu Chi Foundation. Karma [online]. 2014 Nov. 4, [cited 2014]. Available from: http://www.tzuchi.org.tw/index.php?option=com content\&view $=$ article $\&$ id $=8506 \% 3 \mathrm{~A} 2012-04-16-07-21-38 \&$ catid $=\overline{7}$ $1 \% 3$ Amaster-tell-stories\&Itemid=270\&lang $=$ zh.
[42] Farris CS. The social discourse on women's roles in Taiwan: A textual analysis. In: Chen EK, Williams JF, Wong J, Eds. Taiwan, Economy, Society, and History. Hong Kong: Centre of Asian Studies, University of Hong Kong 1991; pp. 285-305.

[43] Strauss A, Corbin J. Basics of qualitative research: grounded theory procedures and techniques. Newbury Park, CA: Sage Publications 1990.

[44] Lincoln YS, Guba EG. Naturalistic Inquiry. Newbury Park, CA: Sage Publications 1985.

(C) Liu and Mishna; Licensee Bentham Open.

This is an open access article licensed under the terms of the Creative Commons Attribution Non-Commercial License (http://creativecommons.org/licenses/by-nc/3.0/) which permits unrestricted, non-commercial use, distribution and reproduction in any medium, provided the work is properly cited. 